Ambiente \& Água - An Interdisciplinary Journal of Applied Science
ISSN 1980-993X - doi:10.4136/1980-993X
www.ambi-agua.net
E-mail: ambi.agua@gmail.com

\title{
Avaliação sazonal da qualidade das águas superficiais do Rio Amazonas na orla da cidade de Macapá, Amapá, Brasil
}

\author{
doi: 10.4136/ambi-agua.1606
}

Received: 17 Feb. 2015; Accepted: 26 May 2015

\author{
Maria da Conceição Silva Damasceno ${ }^{1 *}$; Hebe Morganne Campos Ribeiro ${ }^{1}$; \\ Luís Roberto Takiyama ${ }^{2}$ Manoel Tavares de Paula ${ }^{1}$ \\ ${ }^{1}$ Universidade do Estado do Pará (UEPA), Belém, PA, Brasil \\ Departamento de Ciências Ambientais \\ ${ }^{2}$ Instituto de Pesquisas Científicas e Tecnológicas do Estado do Amapá (IEPA), Macapá, AP, Brasil \\ Centro de Pesquisas Aquáticas \\ *Autor correspondente: e-mail: concedamasceno@ hotmail.com, \\ hebemcr@gmail.com, luistakiyama@hotmail.com,dpaulamt@hotmail.com
}

\section{RESUMO}

A água é primordial à vida na Terra e essencial para a humanidade, porém as múltiplas e complexas atividades humanas alteram este recurso. Este estudo teve como objetivo avaliar as condições físico-químicas e bacteriológicas de água do rio Amazonas na orla de Macapá, Estado do Amapá. O estudo foi realizado em três pontos, no trecho entre a foz do igarapé das Pedrinhas e foz do canal do Jandiá, considerando as variações espaciais e temporais em períodos sazonais. Foram realizadas coletas para análise das seguintes variáveis: turbidez, oxigênio dissolvido, potencial hidrogênionico, temperatura, fósforo total, nitrato, sólidos totais, demanda bioquímica de oxigênio, coliformes termotolerantes e nitrogênio total. Para as análises estatísticas dos dados foram utilizados métodos de Estatística descritiva, teste nãoparamétrico Kruskal-Wallis e Coeficiente de variação. Os resultados obtidos foram avaliados individualmente e comparados com os limites estabelecidos pela Resolução 357/2005 do Conselho Nacional de Meio Ambiente (CONAMA), utilizando como referência "águas doces classe 2". As variáveis DBO e fósforo total apresentaram desconformidade com a resolução. Os resultados do Índice de Qualidade de Água (IQA) indicaram que a água na orla de Macapá, no período menos chuvoso e chuvoso foi classificada, como "boa" e "ótima", onde a turbidez e DBO, foram preponderantes para o decréscimo do IQA na estação menos chuvosa. Conclui-se que no período de menor vazão, o aporte de desejos lançados próximo ao posto de captação de água para o abastecimento público, pode deteriorar a qualidade da água e comprometer a saúde da população.

Palavras-chave: abastecimento de água, efluentes, recursos hídricos, saneamento básico, urbanização.

\section{Seasonal evaluation of the quality of surface waters of the Amazon River on the waterfront of Macapá City, Amapá, Brazil}

\section{ABSTRACT}

Water is essential to life on Earth and crucial for humanity, but multiple and complex human activities alter this resource. This study evaluated the physical-chemical and 
bacteriological water conditions of the Amazon River at the Macapa city waterfront in the State of Amapa. The study was conducted at three points in the section between the mouth of the Igarapé das Pedrinhas and the mouth of the Canal do Jandiá, considering the spatial and temporal variations in seasonal periods. Samples were collected for analysis of the following variables: turbidity, dissolved oxygen, $\mathrm{pH}$, temperature, total phosphorus, nitrate, total solids, biochemical oxygen demand, fecal coliform, and total nitrogen. Descriptive statistical analysis was performed on the data, to include the nonparametric statistical method of Kruskal-Wallis and the coefficient of variation. The results were evaluated individually and compared with the limits established by Resolution 357/2005 of the National Council for the Environment (CONAMA) using "class 2 for fresh water" as a reference. The Biochemical oxygen demand (BOD) values and total phosphorus were not within the resolution threshold. The results of the Water Quality Index (WQI) indicated that during the less rainy and rainy period the water at the Macapa city waterfront was classified as "good" and "excellent", respectively, where the turbidity and BOD were predominant for the decrease in WQI during the less rainy season. It is concluded that in periods of low water flow the contribution of wastewater discharged near the water uptake station for public supply may deteriorate water quality and compromise the health of the population.

Keywords: effluent, urbanization, sewage network, water resources, water supply.

\section{INTRODUÇÃO}

A água é primordial à vida na Terra e essencial para a humanidade (Cech, 2013). Entretanto, as múltiplas e complexas atividades humanas intensificam a alteração deste recurso (Tundisi e Tundisi, 2008), com isso o crescimento exponencial da população, da concentração urbana e do desenvolvimento tecnológico podem contribuir para o aumento do número e intensidade das interferências nos mananciais (Targa e Batista, 2015; Rodrigues et al., 2015; Guerra, 2011).

No Brasil, a maior parte da população é urbana (Silva et al., 2014a; Carmo et al., 2014). Nesse contexto, à medida que a população concentra-se nas cidades, a interferência nos corpos d'água tende a acelerar o processo de degradação hídrica, uma vez que os efluentes domésticos e industriais são as principais fontes de destruição dos mananciais de água doce (Esteves e Menezes, 2011). Desse modo, a urbanização desordenada, pode tornar-se um fator potencial de vulnerabilidade hídrica, uma vez o crescimento urbano não é acompanhado de serviços de saneamento básico (Monteiro et al., 2011).

Para Amazônia, Homma (2005) afirma que $70 \%$ da população da região Norte brasileira é urbana. No Amapá, 90\% de seus habitantes vivem nas cidades. Segundo o autor, as concentrações populacionais localizadas ao longo do rio Amazonas estão transformando seu leito em um grande esgoto das cidades ao longo de sua calha (Manaus, Porto Velho, Parintins, Santarém, Macapá, dentre outras).

O Censo Demográfico do Instituto Brasileiro de Geografia e Estatística (IBGE, 2010) constatou que no Estado do Amapá, houve uma crescente concentração populacional, mas essa dinâmica não foi seguida pelo acesso à rede de esgotamento sanitário (IBGE, 2010). Segundo Santos (2012), embora desde os anos 60 o Estado do Amapá já apresentasse uma população urbana maior que a rural, a partir da década de 80 houve um crescimento acelerado, favorecido pelo intenso processo migratório que ocorreu devido, entre outros fatores, à transformação do território em Estado (1988) e posteriormente (1992) à criação da Área de Livre Comércio de Macapá e Santana (ALCMS).

Para Takiyama et al. (2007), as ações humanas podem estar comprometendo a qualidade ambiental dos recursos hídricos no município de Macapá, principalmente nas áreas de maior ocupação 
Estudos de Pinheiro et al. (2008) afirmaram que potenciais problemas de poluição na zona estuarina desta cidade, podem representar risco ao sistema de abastecimento público de água do estado do Amapá.

Carmo et al. (2014) afirmaram que em 2000, Macapá, capital do Estado do Amapá, possuía naquele ano, um dos mais altos níveis de consumo de água per capita, o que correspondia a $184 \mathrm{~L} /$ hab. / dia. O que leva a crer que passado14 anos tal consumo pode não ter sido acompanhado pela ampliação e melhoria da qualidade de serviços de saneamento básico.

O rio Amazonas, na orla de Macapá, possui fins múltiplos (Sousa e Cunha, 2013; Pinheiro et al., 2008), tais como fonte principal de abastecimento público, receptor de refluxo do sistema de captação e abastecimento de água da cidade (Companhia de Água e Esgoto do Amapá), de água de drenagem fluvial e de esgoto doméstico. É utilizado também, dentre outros, como via de navegação de embarcações de pequeno, médio e grande porte de procedências locais, nacionais e internacionais, porto e recreação.

A referida orla, além da pressão urbana local, sofre influências de procedências fluviais (regime da descarga líquida), pluviais (precipitações sazonais) e oceânicas (efeito de marés) (Torres e El-Robrini, 2006) e, ainda, perturbações antropogênicas provenientes das inúmeras atividades desenvolvidas no seu entorno.

A cidade é cortada por diversos canais (naturais) de drenagens (Silva e Alburquerque, 2013) que ligam as áreas de Ressacas (áreas úmidas) ao rio Amazonas. Tais canais, com o uso e ocupação inadequada do solo ao longo de seu curso, podem alterar a qualidade da água.

$\mathrm{O}$ crescimento espacial desordenado e acelerado e, consequentemente, a escassez de serviços de saneamento básico, são responsáveis por tais alterações (Pereira et al., 2010b). Além disso, a intervenção antropogênica nos ambientes lóticos, perto de áreas urbanas pode ser um fator importante que afeta a biota do rio, (Machado et al., 2015).

Nesse sentido, as relações e inter-relações inerentes às cidades criam diversidades de ações que, se não bem administradas, podem causar grandes transtornos às áreas urbanas (Tucci, 2008) e a sustentabilidade do corpo hídrico (Portugal Júnior et al., 2015).

Com base nesses pressupostos, as questões que nortearam este estudo foram: como se encontra a qualidade da água na orla de Macapá, em face ao crescimento desordenado da urbanização? Esse corpo hídrico está de acordo com os limites estabelecidos pela Resolução CONAMA 357/05 (CONAMA, 2005).

O presente estudo teve como objetivo avaliar as condições físico-químicas e bacteriológicas da água de superfície do rio Amazonas na orla de Macapá, Amapá.

\section{MATERIAL E MÉTODOS}

\section{1. Área de Estudo}

A área de estudo está localizada à margem esquerda do rio Amazonas denominado, também, de canal norte do rio Amazonas e Setor Costeiro Estuarino ou amazônico, na orla do município de Macapá, capital do Estado do Amapá, no extremo norte do Brasil.

Macapá concentra o maior índice populacional do Estado, com 398.204 habitantes em uma área de aproximadamente $6.408,545 \mathrm{~km}^{2}$ (IBGE, 2010). Possui clima quente e úmido, com a existência de duas estações bem definidas de precipitação: estação menos chuvosa de agosto a novembro e a estação chuvosa de dezembro a julho quando ocorre $90 \%$ do total anual de precipitação (Tavares, 2014). Essa região não apresenta grandes diferenças de temperaturas ao longo do ano e a temperatura média anual varia entre $26^{\circ} \mathrm{C}$ e $27^{\circ} \mathrm{C}$. De acordo com os dados do Instituto Nacional de Meteorologia (INMET, 2014), as temperaturas mais elevadas ocorrem entre os meses de julho a dezembro. A umidade relativa média anual do ar varia em torno de $80 \%$ a $90 \%$, indicando, assim, uma alta taxa de umidade na região. 
$\mathrm{O}$ rio Amazonas possui uma descarga hídrica de $5.7 \times 10^{12} \mathrm{~m}^{3}$. ano ${ }^{-1}$. Entretanto, a descarga máxima e mínima alcança, respectivamente, $220.000 \mathrm{~m}^{3} \cdot \mathrm{s}^{-1} \mathrm{em}$ maio e $100.000 \mathrm{~m}^{3} \mathrm{~s}^{-1}$ em novembro (Santos et al., 2007). A costa estuarina em Macapá possui uma dinâmica influenciada pela descarga hídrica e sólida do rio Amazonas, pelas correntes de maré e pela ação antropogênica proveniente da urbanização acelerada e desordenada no seu entorno.

São observadas, no espaço urbano, áreas de "ressacas" (úmidas), influenciadas pela maré. Tais áreas sofrem diversos impactos causados por construção de moradias, aterramento, queimadas, despejos de resíduos sólidos e dejetos, e entre outros (Takiyama et al., 2003).

\subsection{Localização e caracterização dos pontos de coleta}

Foram selecionados três pontos de coletas que possibilitassem a análise do comportamento espacial e temporal do corpo d'água no trecho compreendido entre a foz do Igarapé das Pedrinhas e do Canal do Jandiá (8.85 km), no Rio Amazonas, na orla de Macapá, conforme pode ser observada na Figura 1.

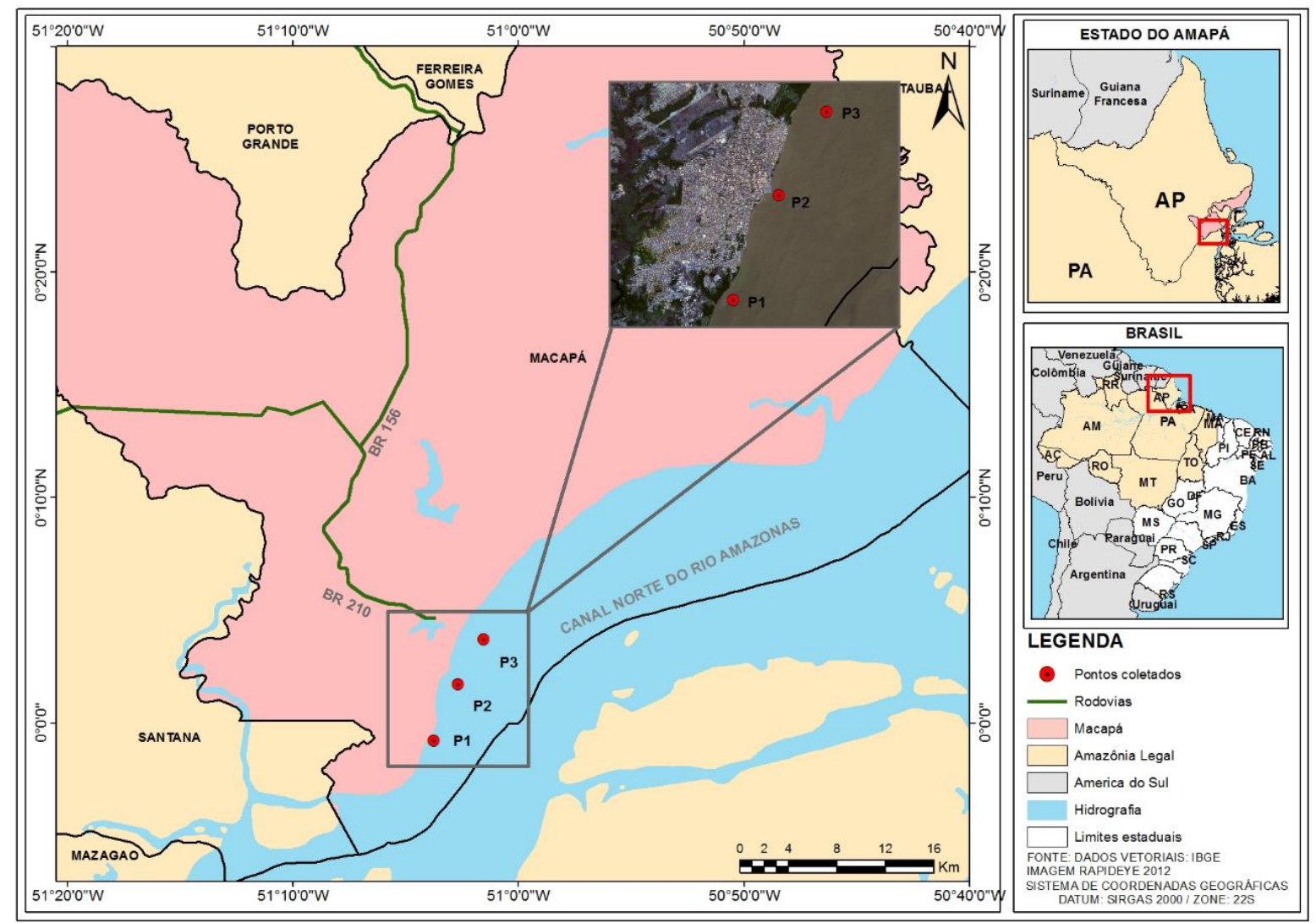

Figura 1. Localização do Canal Norte do rio Amazonas, orla de Macapá, AP.

Para avaliar a dinâmica espacial, foi levado em consideração o possível risco de contaminação proveniente do inadequado uso e ocupação do solo, da escassez de saneamento básico e do lançamento de efluentes diretamente no corpo d'água (cargas pontuais de origem doméstica). Para tal, foram selecionados dois pontos (P1 e P2) localizados mais próximo possível dos lançamentos dos efluentes (500 $\mathrm{m}$ da margem), pois os bancos de areia presentes impossibilitaram a escolha de uma distância menor, e um ponto (P3) situado à $1500 \mathrm{~m}$ da margem. Este foi escolhido como um provável ponto de menor influência da poluição urbana. O esquema temporal foi baseado no ciclo de maré e no regime pluvial. 
Os três pontos de amostragem foram georeferenciados com auxílio de GPS Garmin (modelo GPSmap 62SC) e caracterizados como P1, P2 e P3 como pode ser observado na Figura 1. Para a atividade de campo, foram montadas e treinadas três equipes de coletas.

O P1 está localizado ao sul da cidade de Macapá. A coleta foi realizada a 500 metros da margem esquerda do rio Amazonas na confluência com o Canal das Pedrinhas, o qual atravessa vários bairros do município, interage diretamente com o rio Amazonas e áreas de "ressacas". No entorno se encontra a bacia de decantação, onde são lançados, de forma in natura, dejetos das fossas da capital. Também, ao longo de sua calha, pode ser encontrado além de espaços residenciais ditos convencionais, moradias denominadas de palafitas, madeireiras, porto para atracação de barcos de pequeno porte, posto de combustível, estaleiros, entre outros.

O ponto P2 está situado próximo ao posto de captação de água para o abastecimento público de Macapá (na orla do bairro Santa Inês) onde a coleta também foi realizada a 500 metros da margem. Nesse local, pode ser encontrado vários efluentes que são diretamente lançados no rio Amazonas, inclusive os dejetos da própria Companhia de Água e Esgoto do Amapá (CAESA).

Em seus arredores há concentração de bares, restaurantes, rampa para atracação de embarcações de pequenos portes, presença de canal artificial e importantes pontos turísticos, bem como áreas utilizadas pelos moradores para fins de recreação.

O ponto P3 está localizado nas proximidades do Canal do Jandiá e do Igarapé das Mulheres, ao norte da cidade de Macapá, a 1500 metros da margem. Este canal, assim como o P1, passa por vários bairros, todos quase sem infraestrutura. Em seu entorno, podem ser encontradas edificações para moradias e destinadas às atividades comercias e serviços, como feira livre, madeireiras, oficinas mecânicas, portos de pequenos portes provenientes de diversas regiões ribeirinhas dos Estados do Pará e Amapá.

\subsection{Amostragem de campo}

O trabalho de campo foi efetivado com a realização de duas campanhas: a primeira no período de descarga fluvial mínima do rio Amazonas, $100.000 \mathrm{~m}^{3}$, (Novembro/2013 - período menos chuvoso) e a segunda no período de descarga máxima, $220.000 \mathrm{~m}^{3}$ (Maio/2014 período chuvoso).

Em cada campanha, as coletas foram feitas na parte superficial da água a, aproximadamente, $20 \mathrm{~cm}$ abaixo da lâmina d'água. $\mathrm{O}$ armazenamento e acondicionamento das amostras seguiram metodologia estabelecida pela CETESB (2013), bem como pelas exigências estipuladas pelos laboratórios responsáveis pelas análises: Ecolabor, Laboratório de Análise Química Mineral, Ambiental e Industrial (ANQUIM) e IEPA (Instituto de Pesquisas Científicas e Tecnologia do Amapá). Para isso, cada laboratório enviou os seus recipientes devidamente etiquetados e preparados para o recebimento de suas respectivas amostras, as quais, posteriormente, foram depositadas em seus devidos frascos e volumes, acondicionadas em isopor e refrigeradas a $4^{\circ} \mathrm{C}$, até posterior análise nos laboratórios, as quais aconteceram dentro dos prazos de validade, de acordo com os protocolos de amostragem e análise de corpos d'água, padronizada pelo Standard Methods for Water and Wastewater (APHA et al., 2005).

Durante os dois períodos sazonais todas as coletas aconteceram simultaneamente nos três pontos, conforme descrito na Tabela 1. Para observar as alterações provocadas pela dinâmica da maré foi empregada a tábua de maré, fornecida pela Diretoria de Hidrografia e Navegação (DHN), Centro de Hidrografia da Marinha (CHM) e pelo Banco Nacional de dados Oceanográficos (BNDO). 
Tabela 1. Descrição das amostragens de campo em ambos os períodos (chuvoso e menos chuvoso).

\begin{tabular}{ccccc}
\hline Coletas & $\mathrm{P} 1 / \mathrm{H}$ & $\mathrm{P} 2 / \mathrm{H}$ & $\mathrm{P} 3 / \mathrm{H}$ & Maré \\
\hline 1 & $07: 00$ & $07: 00$ & $07: 00$ & vazante \\
2 & $09: 00$ & $09: 00$ & $09: 00$ & vazante \\
3 & $11: 00$ & $11: 00$ & $11: 00$ & baixa mar \\
4 & $13: 00$ & $13: 00$ & $13: 00$ & enchente \\
5 & $15: 00$ & $15: 00$ & $15: 00$ & enchente \\
6 & $17: 00$ & $17: 00$ & $17: 00$ & preamar \\
\hline
\end{tabular}

Nota: O P1, P2, e P3 representam os pontos de amostragem e o $\mathrm{H}$ a hora da coleta.

\subsection{Análises das variáveis}

As variáveis turbidez, OD, $\mathrm{pH}$ e temperatura, foram mensuradas in loco e fósforo total, nitrato, DBO e nitrogênio total foram analisadas no laboratório Ecolabor, em São Paulo, devidamente certificado pelo Instituto Nacional de Metrologia, Qualidade e Tecnologia (INMETRO), enquanto as variáveis coliformes termotolerantes, foram analisados pelo Laboratório ANQUIM e os sólidos totais pelo IEPA, ambos em Macapá-AP. As metodologias analíticas utilizadas estão elucidadas na Tabela 2.

Tabela 2. Parâmetros físico-químicos e equipamentos utilizados na determinação das variáveis.

\begin{tabular}{llc}
\hline Variáveis & \multicolumn{1}{c}{ Metodologia analítica } & $\begin{array}{c}\text { Local de } \\
\text { análise }\end{array}$ \\
\hline Turbidez $(\mathrm{UNT})$ & AgSolve Sonda Aquaread AP-2000 e leitor Aquameter & In loco \\
OD $(\mathrm{mg} / \mathrm{L})$ & AgSolve Sonda Aquaread AP-2000 e leitor Aquameter & In loco \\
$\mathrm{pH}$ & AgSolve Sonda Aquaread AP-2000 e leitor Aquameter & In loco \\
Temperatura $\left({ }^{\circ} \mathrm{C}\right)$ & AgSolve Sonda Aquaread AP-2000 e leitor Aquameter & In loco \\
Fósforo Total $(\mathrm{mg} / \mathrm{L})$ & SMEWW 22 ${ }^{\mathrm{a}}$ Ed. - Método(s): $4500-\mathrm{P}$ E & Ecolabor \\
Nitrato (mg/L) & USEPA - 300.1, 1997 & Ecolabor \\
Sólidos Totais & Methods: SMEWW 2540 D & IEPA \\
DBO & SMEWW 22 ${ }^{\mathrm{a}}$ Ed. - Método(s): $5210 \mathrm{~B}$ & Ecolabor \\
Colifor.Termo.(NMP/100 ml) & SM 9222 A, B, C, D & ANQUIM \\
Nitrogênio Total $(\mathrm{mg} / \mathrm{L})$ & SMEWW 22 & Ecolabor \\
\hline
\end{tabular}

\subsection{Análise dos dados}

Para obter o perfil das variáveis foi utilizado a estatística descritiva (média, mediana, mínimo e máximo) e para testar as diferenças entre pontos e períodos sazonais teste não-paramétrico Kruskal-Wallis, e Coeficiente de variação para o IQA. O estudo admitiu o 
nível de significancia de $\mathrm{p}<0,05$. Os softwares Bioestat ${ }^{\circledR} 5.0$ (Ayres et.al., 2008) e Excel 2010 foram usados para as análises estatísticas. Para construção dos gráficos foi utilizado Origin versão 8.

As variáveis estudadas como turbidez, oxigênio dissolvido (OD), potencial hidrogênionico $(\mathrm{pH})$, temperatura, fósforo total, nitrato, sólidos totais, demanda bioquímica de oxigênio (DBO) e coliformes termotolerantes, foram avaliadas individualmente e comparadas com os limites estabelecidos pela Resolução 357/05 do Conselho Nacional de Meio Ambiente - CONAMA (2005). Posteriormente, estas variáveis foram aplicadas no cálculo do IQA, exceto o nitrato que foi substituído pelo nitrogênio total e o fósforo total pelo fosfato.

De acordo Von Sperling (2008), o IQA não é um instrumento de avaliação de atendimento à legislação ambiental, mas de comunicação para o público das condições ambientais do corpo d'água. O IQA é calculado pelo produtório ponderado das qualidades de água correspondentes às variáveis que integram o índice. Para tal, a seguinte fórmula é utilizada:

$$
\mathrm{IQA}=\prod_{\mathrm{i}=1}^{\mathrm{n}} \mathrm{q}_{\mathrm{i}}^{\mathrm{w}_{\mathrm{i}}}
$$

em que:

IQA, é Índice de Qualidade das Águas, um número entre 0 e 100;

Qi, é qualidade do i-ésimo parâmetro, um número entre 0 e 100, obtido da respectiva "curva média de variação de qualidade" em função de sua concentração ou medida;

Wi, é peso correspondente ao i-ésimo parâmetro, um número entre 0 e 1 , atribuído em função da sua importância para a conformação global de qualidade e o

i refere-se ao $\mathrm{n}^{\mathrm{o}}$ do parâmetro variando de 1 a 9.

A qualidade da água é classificada por faixas de IQA, conforme a Tabela 3.

Tabela 3. Classificação do IQA - segundo CETESB.

\begin{tabular}{llc}
\hline Nível & Cor & Faixa de IQA \\
\hline Ótima & Azul & $79<$ IQA $\leq 100$ \\
Boa & Verde & $51<$ IQA $\leq 79$ \\
Aceitável & Amarela & $36<$ IQA $\leq 51$ \\
Ruim & Vermelha & $19<$ IQA $\leq 36$ \\
Péssima & Preta & IQA $\leq 19$ \\
\hline
\end{tabular}

Fonte: Von Sperling (2008).

\section{RESULTADOS E DISCUSSÃO}

\subsection{Resultados por variável}

Para a turbidez (Figura 2A), no período menos chuvoso, a mediana foi de 68,95 UNT com valores numéricos variando de 63,7 a 70,0 UNT e no chuvoso, de 29,80 UNT, com 
valores mínimo de 24,2 e máximo de 34,6 UNT. Como referência, os estudos de Silva et al. (2014b) no rio Guamá, no Estado do Pará, encontraram durante o período chuvoso níveis de turbidez de 27,4 UNT, ou seja, valores próximos aos detectados neste estudo.

$\mathrm{O}$ teste Kruskal-Wallis ou teste $\mathrm{H}$ inferiu que houve diferença significativa $(\mathrm{H}=28.930$ e $\mathrm{p}=0.0001$ ) entre os pontos P1 no período menos chuvoso com os três pontos, no chuvoso, e entre P2 na estação menos chuvosa com P1 na estação chuvosa.

Os resultados apontam que no período de menor vazão, os pontos (P1 e P2) localizados mais próximos da margem e do posto de captação de água para o abastecimento público, apresentaram maiores valores de turbidez no período menos chuvoso. Neste período, a água está mais vulnerável à interferência antrópica, (Pereira et al., 2010), podendo comprometer a saúde pública. Conforme, Silva e Araújo (2003), a turbidez pode se fixar aos patógenos existentes, e dificultar a ação do cloro sobre os mesmos.

As águas superficiais em rios estuarinos apresentam redução de teores dessa variável na estação chuvosa, podendo ser decorrente do aumento da vazão, pois a estação de maior oferta pluvial favorece a diluição e a autodepuração das águas (Cunha et al., 2005).

Resultados contrário foram detectados por Santi et al. (2012) no Igarapé São Francisco em Rio Branco, capital do Estado do Acre, onde maiores valores foram encontrados no período chuvoso. Tal resultado pode ser explicado pelo fato do igarapé possuir menor vazão, comparado ao grande volume hídrico do rio Amazonas.

Quanto a legislação, o valor limite da turbidez estabelecido pelo CONAMA, 357/05 (CONAMA, 2005) para águas doces de Classe 2 é de 100 UNT. Logo, os valores encontrados na orla de Macapá estão em conformidade com a resolução.

Os fatores que controlam a concentração de oxigênio são a temperatura, corrente, luz, pressão, e a matéria orgânica (Esteves e Menezes, 2011). Para o oxigênio dissolvido, foi observado, (Figura 2B), que o período menos chuvoso e chuvoso apresentou mediana de $7,18 \mathrm{mg} \mathrm{L}^{-1}$ e $6,52 \mathrm{mg} \mathrm{L}^{-1}$, respectivamente.

$\mathrm{Na}$ estação menos chuvosa a presença de vento se mostrou mais forte e constante, o que pode ter favorecido uma maior dissolução de oxigênio da atmosfera para a água. Por outro lado, durante o período de chuva há um aumento da matéria orgânica dissolvida e particulada onde esta se origina pela própria ressuspensão do sedimento ou a partir das águas dos tributários, que podem estar recebendo descargas de esgotos, e águas de escoamento superficial, resultando em um aumento da matéria orgânica que por sua vez, pode reduzir os níveis de OD (Rodrigues et al., 2015; Esteves, 2011; Takiyama et al., 2003).

Houve diferença estatística significativa $(\mathrm{H}=27.5487$ e $\mathrm{p}=0.0001)$ no $\mathrm{P} 1$ no período menos chuvoso com relação aos três pontos estudados na estação chuvosa. Bem como, no P2 no período menos chuvoso com o P1 e P2 no chuvoso. O teste inferiu que a estação com maior oferta pluvial favoreceu menor concentração de OD nos pontos 1 e 2 , localizados mais próximos da interferência urbana.

Comparado os valores de OD obtidos com o limite estabelecido pela Resolução CONAMA 357/05 (CONAMA, 2005), que estipula que o valor de OD não deve ser inferior a $5 \mathrm{mg} \mathrm{L}^{-1}$ para as águas doce da classe 2 , o ambiente aquático em questão, nos dois períodos estudados, está de acordo com o limite estipulado pela referida resolução.

De acordo com a Figura 2C, o pH apresentou mediana de 6,31 e 6,00 no período menos chuvoso e chuvoso respectivamente. Pontes et al. (2012) observaram na micro-bacia do Córrego Banguelo, no Estado de Minas Gerais que a maioria dos pontos monitorados, apresentou água mais ácida também no período de chuvas, o que pode estar associada ao aumento no teor de ácidos orgânicos. Valores similares foram encontrados por Santi et al. (2012) no Igarapé São Francisco no Estado do Acre durante o período de alta pluviosidade. Os autores enfatizam que os resultados são explicados, pelo fato das águas da precipitação atmosférica serem mais ácidas. 
Houve diferença estatística significativa $(\mathrm{H}=17.0292$ e p $=0.0044)$ do $\mathrm{pH}$, no P3 (1500 metros da margem) durante o período menos chuvoso comparado ao P1 (500 metros da margem) no período chuvoso. Por mais que acidez seja uma característica natural dos rios amazônicos, (Silva et al., 2008), os resultados indicam que a água no período chuvoso, próximo ao canal das Pedrinhas, se apresentou mais ácida comparada ao período menos chuvoso. Com isso, no P1, o aumento da acidez no período de maior oferta pluvial, pode ser de origem alóctone (despejos ou carreamento urbano).

Houve diferença estatística significativa $(\mathrm{H}=17.0292$ e $\mathrm{p}=0.0044)$ do $\mathrm{pH}$, no P3 (1500 metros da margem) durante o período menos chuvoso comparado ao P1 (500 metros da margem) no período chuvoso. Tais resultados indicam que a água no período chuvoso, próximo ao canal das Pedrinhas, se apresentou mais ácida comparada ao período menos chuvoso. Porém, esta acidez parece ser uma característica própria dos rios da Amazônia e aparentemente, não influenciam negativamente na qualidade das águas (Silva et al.,2008).

De acordo com a Resolução CONAMA 357/05 (CONAMA, 2005), a água do rio Amazonas na orla de Macapá, é classificada como Classe 2. Para esse tipo de água, esta resolução estipula que a faixa de $\mathrm{pH}$ deve ser de 6.0 a 9.0. Portanto, tais resultados estão dentro da faixa de valores preconizados pela resolução.
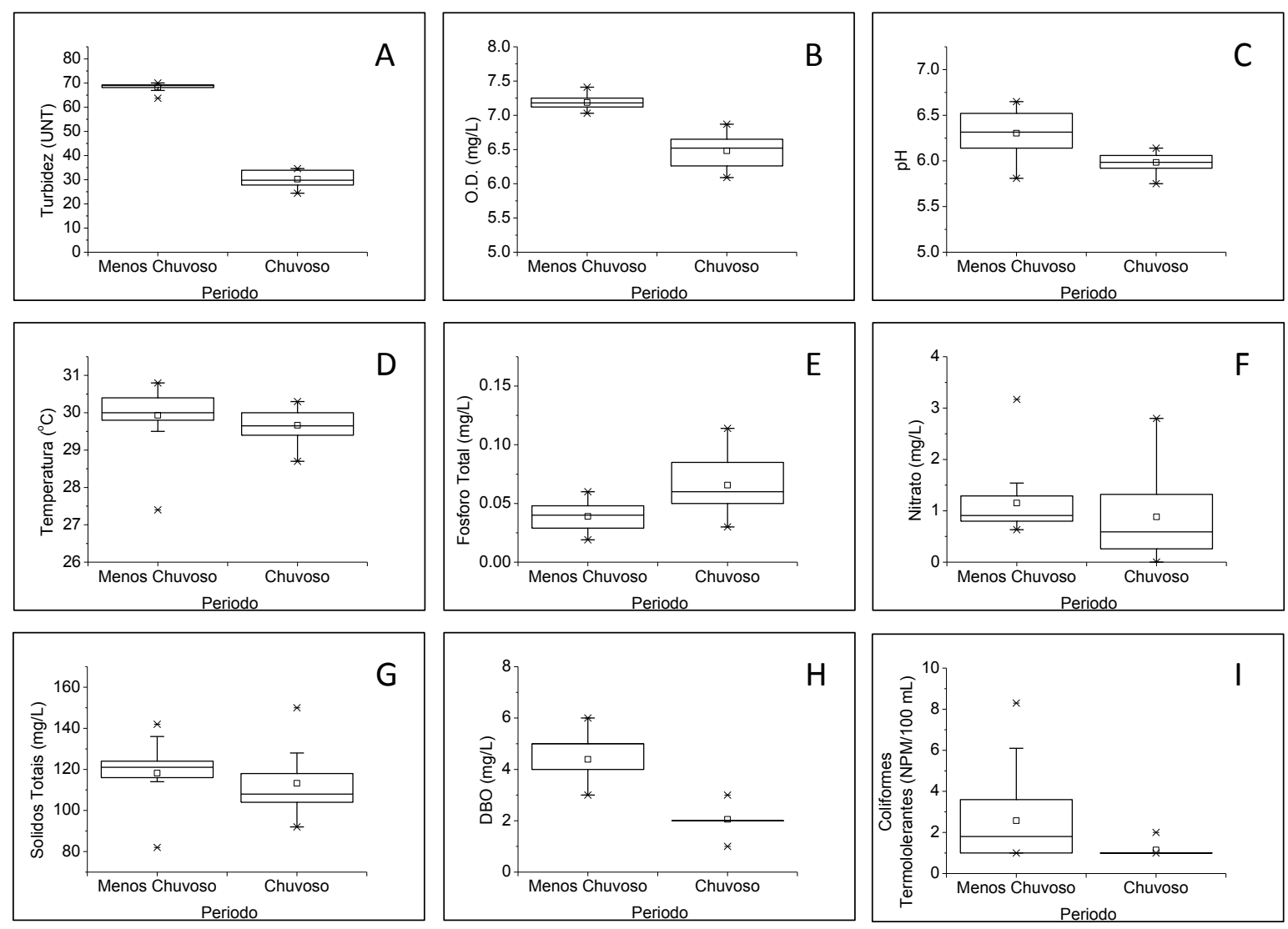

Figura 2. Distribuição sazonal dos parâmetros: turbidez (A), oxigênio dissolvido (B), pH (C), temperatura (D), fósforo total $(\mathrm{E})$, nitrato $(\mathrm{F})$, sólidos totais $(\mathrm{G})$, DBO $(\mathrm{H})$, coliforme termotolerante (I) durante os períodos menos chuvoso (2013) e chuvoso (2014).

No que se refere a temperatura, não houve diferença estatística significativa $(\mathrm{H}=5.0093$ e $\mathrm{p}=0.4147$ ) entre os pontos e nem entre as estações (Figura 2D). Oscilando no período menos chuvoso com máxima de $31^{\circ} \mathrm{C}$ e no período chuvoso na faixa $29,5^{\circ} \mathrm{C}$. Este fato foi constatado também por Alves et al. (2012), no rio Arari, na Ilha de Marajó-Pará, em que a temperatura das águas superficiais nesse manancial é característica natural das águas 
amazônicas, onde sua maior amplitude térmica acontece ao longo do dia e não em sazonalidades diferentes.

O CONAMA 357/05 (CONAMA, 2005), estabelece como limite o valor de $40^{\circ} \mathrm{C}$. Desta forma, os valores encontrados neste estudo estão de acordo com a legislação consultada.

Com relação aos resultados observados em períodos distintos, o fósforo total (Figura 2E), expressou medianas 0,04 e $0,06 \mathrm{mg} \mathrm{L}^{-1}$ nos períodos menos chuvoso e chuvoso, respectivamente. Essa variável apresentou diferença significativa entre as estações, $(\mathrm{H}=16.1656$ e $\mathrm{p}=0.0064)$. Resultados similares foram encontrados por Siqueira et al. (2012) no rio Parauapebas-Pará.

O fósforo presente nos corpos d'água pode ter procedências naturais ou antrópicas. De acordo com Von Sperling (2008), as principais fontes de fósforo em um corpo d'água são a drenagem pluvial (áreas com matas e florestas, agrícolas e urbanas) e esgotos. Considerando que a maior concentração de fósforo coincidiu com o período chuvoso (fonte difusa), possivelmente sua origem pode ser de processos naturais, da dissociação dos sedimentos em suspensão e da lixiviação do solo pelas águas das chuvas, (Marins et al., 2007; Santos et al., 2010).

O limite estabelecido pela CONAMA 357/05 (CONAMA, 2005), é de 0,1 mg L $\mathrm{m}^{-1}$. Logo, os teores encontrados na estação chuvosa estão em desacordo com a Resolução.

Para a concentração de nitrato (Figura $2 \mathrm{~F}$ ), o maior valor encontrado foi de $3,17 \mathrm{mg} \mathrm{L}^{-1}$ no período menos chuvoso no P3. Valores máximos de $128 \mathrm{mg} \mathrm{L}^{-1}$ foram detectados por Fagundes et al. (2010) no rio Araguari-AP durante o período chuvoso. Para esta variável, não houve diferença significativa entre os pontos e nem entre as campanhas $(\mathrm{H}=9.7375$ e $\mathrm{P}=$ 0.0830). Considerando o limite de $10,0 \mathrm{mg} \mathrm{L}^{-1}$ para água de Classe 2 , a concentração detectada na orla de Macapá encontra-se em conformidade com a resolução CONAMA 357/05 (CONAMA, 2005).

Os sólidos totais (Figura 2G), apresentaram medianas 65, 25 e 65,50, nos períodos menos chuvosos e chuvosos, respectivamente. Portanto, não houve diferença significativa entre os pontos e nem entre as estações $(\mathrm{H}=6.4189$ e $\mathrm{p}=0.2676)$. Diferente de Fagundes et al. (2010) que detectou maiores concentrações na estação chuvosa.

Embora a resolução CONAMA 357/05 (CONAMA, 2005) não trate dessa variável, explica que é peculiar dos rios amazônicos apresentarem altos teores de matéria orgânica em suas águas, o que ocorre em virtude de processos naturais que envolvem o bioma.

Conforme a Figura $2 \mathrm{H}$, foi observado que a demanda bioquímica de oxigênio, (DBO) apresentou mediana $5 \mathrm{mg} \mathrm{L}^{-1}$ e $2 \mathrm{mg} \mathrm{L}^{-1}$ no período menos chuvoso e chuvoso respectivamente. $\mathrm{O}$ teste $\mathrm{H}$ afirma que houve diferença estatística significativa $(\mathrm{H}=29.1424 \mathrm{e}$ $\mathrm{p}=0.0001$ ), entre P2 no período menos chuvoso com os demais pontos na estação chuvosa e o P3 (menos chuvosa) e o P2 (chuvosa) com menor concentração da DBO na estação chuvosa.

Durante a estação menos chuvosa o $\mathrm{P} 2$, localizado na proximidade do posto de captação de água para abastecimento público, pode estar evidenciando possíveis perturbações. Neste período, os resultados indicam uma maior presença de matéria orgânica na água, provavelmente pelo despejo de esgoto (CETESB, 2009). Quanto ao P3, (ponto localizado à $1.500 \mathrm{~m}$ da margem) também, na estação menos chuvosa, apresentou maior concentração de DBO, comparado ao P2 na estação chuvosa. Este efeito indica que a vazão do rio Amazonas pode oferecer capacidade de diluição e autodepuração do corpo hídrico e que o P3 pode ser referência como zona de menor carga de poluidora de origem urbana.

Nos estudos de Alves et al. (2012) no rio Arari, ilha do Marajó-PA e Oliveira e Cunha (2014) no Baixo Rio Jari-AP, os maiores valores foram detectados durante o período chuvoso, devido ao processo de ressuspensão ou por ação das marés altas que inundam as margens e carreiam materiais orgânicos para o rio. No caso da orla de Macapá, sugere-se que o aumento 
da DBO na estação menos chuvosa pode estar atrelado à interferência antropogênica proveniente do inadequado uso e ocupação do solo e do lançamento de efluentes domésticos in natura no manancial.

O corpo d'água em questão apresentou valor máximo de $6 \mathrm{mg} \mathrm{L}^{-1}$ durante o período menos chuvoso. Tal resultado insere o corpo d'água analisado acima do permitido pelo CONAMA/357/05 (CONAMA, 2005), onde o máximo até $5 \mathrm{mg} \mathrm{L}^{-1}$.

Para os coliformes termotolerantes na Figura 2I, entre as duas campanhas os valores mais altos foram observados na estação menos chuvosa, com máxima de $8.0 \mathrm{NMP}$ em $100 \mathrm{ml}^{-1}$ para esta variável. Pereira et al. (2010a), encontraram no rio Caeté na Amazônia brasileira, maiores valores também nesta estação, de acordo com os autores, neste período, a baixa taxa de precipitação, diminui a vazão e favorece maior concentração de efluentes no manancial, o que pode contribuir para elevar os valores dos coliformes.

Nos estudos de Haddad e Magalhães Júnior (2010) no rio São Miguel, em Minas Gerais, picos de concentrações de coliformes termotolerantes se apresentaram durante a estação chuvosa.

Conforme o teste $\mathrm{H}$ a variável coliforme termotolerante não apresentou diferenças significativas entre os pontos e nem entre as estações $(\mathrm{H}=9.8743$ e $\mathrm{p}=0.7890)$. A resolução CONAMA 357/05 estabelece limite de $1000 \mathrm{NMP}$ em $100 \mathrm{~mL}^{-1}$ para este parâmetro. Logo, pode-se concluir que os coliformes termotolerantes estão em acordo com os limites da referida legislação (CONAMA, 2005) para Classe 2 de águas doces.

\subsection{Resultados dos Cálculos de Índice de Qualidade das Águas (IQA)}

Após a aplicação do teste não-paramétrico, Coeficiente de variação, com p-valor $=0.0272$, pode-se afirmar que as diferenças entre as médias das campanhas são estatisticamente significativas com relação ao IQA (Tabela 4). Entretanto, com relação aos pontos em um mesmo período sazonal, não houve diferença estatística significativa $(\mathrm{P}>0,05)$.

Tabela 4. Distribuição do IQA segundo a média, desvio padrão e CV\% (Coeficiente de Variação em percentagem) segundo os pontos de coletas P1, P2 e P3.

\begin{tabular}{lcccccc}
\hline & \multicolumn{5}{c}{ Índice de qualidade da água } \\
\cline { 2 - 7 } Coleta & $\begin{array}{c}\text { Menos } \\
\text { chuvoso }\end{array}$ & DP & CV & Chuvoso & DP & CV \\
\hline Ponto-P1 & 76.54 & \pm 3.94 & $5.15 \%$ & 81.14 & \pm 0.94 & $1.15 \%$ \\
Ponto-P2 & 78.02 & \pm 1.01 & $1.30 \%$ & 80.82 & \pm 2.26 & $2.80 \%$ \\
Ponto-P3 & 75.55 & \pm 2.47 & $3.26 \%$ & 81.02 & \pm 2.02 & $2.49 \%$ \\
\hline Média & $\mathbf{7 6 . 7 0}$ & $\pm \mathbf{1 . 0 1}$ & $\mathbf{1 . 6 2 \%}$ & $\mathbf{8 0 . 9 3}$ & $\mathbf{\pm 0 . 1 6}$ & $\mathbf{0 . 2 0 \%}$ \\
\hline
\end{tabular}

Ao comparar os dois períodos (Figura 3), a estação chuvosa apresentou melhor índice de qualidade. Esta comprovação pode ser explicada pela diluição dos contaminadores no período de chuva. Embora a descarga de efluentes sem tratamento seja constante, o aumento da vazão devido às chuvas, podem ocasionar a diluição (Pereira et al., 2010a; Sabino et al., 2008). 


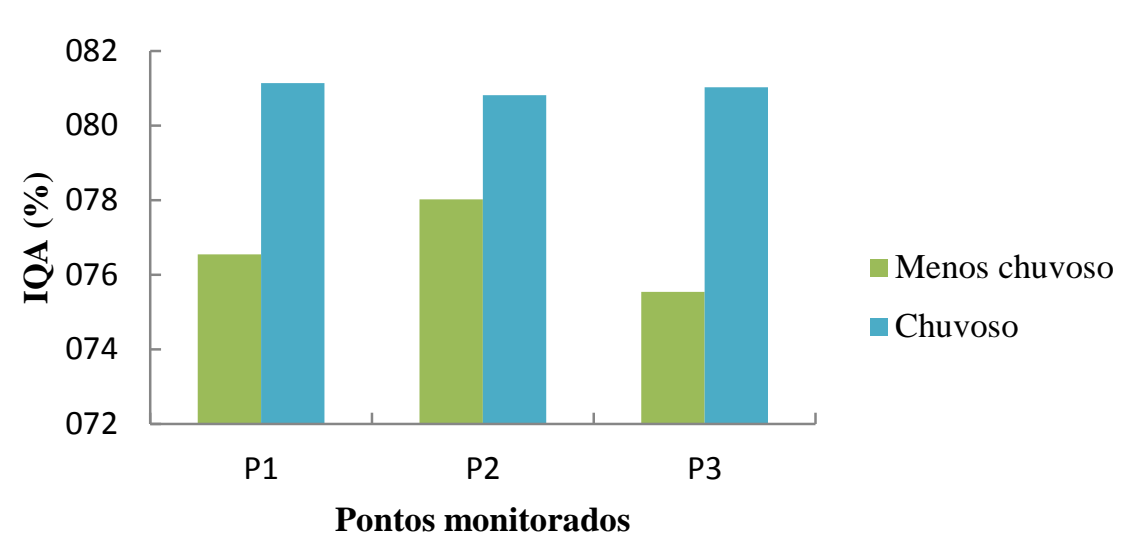

Figura 3. Distribuição sazonal do IQA.

Os resultados do Índice de Qualidade de Água (IQA) no período menos chuvoso e chuvoso se encontraram na faixa de $70<$ IQA $<90$ e $90<$ IQA $\leq 100$, respectivamente. Portanto classificado de acordo com a CETESB (Von Sperling, 2008) na qualidade de "boa" e "ótima”.

\section{CONCLUSÃO}

As análises do teste não-paramétrico Kruskal-Wallis identificaram as variáveis turbidez e demanda bioquímica de oxigênio nos pontos mais próximos do espaço urbano (P1 e P2), como sendo fatores de evidências de degradação hídrica, durante o período menos chuvoso.

Ao comparar os resultados deste estudo com os valores recomendados pela resolução CONAMA 357/05 para "águas doces classe 2", apenas as variáveis DBO e fósforo total apresentaram desconformidade com a resolução.

A oferta hídrica do rio Amazonas, somado às influências pluvial e oceânica apontam condição de dispersão, diluição e autodepuração do corpo d'água estudado.

O Coeficiente de Variação aplicado ao Índice de Qualidade de Água (IQA) indicou que a variação sazonal foi relevante para que houvesse diferenças estatisticamente significativas entre os períodos distintos.

No período de menor vazão, o aporte de desejos lançados in natura próximo ao posto de captação de água para o abastecimento público pode deteriorar a qualidade da água e comprometer a saúde da população.

\section{AGRADECIMENTOS}

Ao Programa de Pós Graduação em Ciências Ambientais (PPGCA) da Universidade do Estado do Pará (UEPA) pela oportunidade de cursar o mestrado.

Ao Instituto de Pesquisas Científicas e Tecnológicas do Amapá - IEPA, pela concessão de alunos bolsistas para auxiliar nas coletas, lanchas, bem como, pelas análises da variável sólidos totais.

\section{REFERÊNCIAS}

ALVES, I. C. C.; EL- ROBRINI, M.; SANTOS, M. L. S.; MONTEIRO, S. M. BARBOSA, L. P. F.; GUIMARÃES, J.T. F. Qualidade das águas superficiais e avaliação do estado trófico do Rio Arari (Ilha de Marajó, norte do Brasil). Acta Amazônica, v. 42, n. 1, p. 115-124, 2012. http://dx.doi.org/10.1590/S0044-59672012000100014 
AMERICAM PUBLIC HEALTH ASSOCIATION - APHA; AMERICAN WATER WORKS ASSOCIATION - AWWA; WATER ENVIRONMENT FEDERATION - WEF. Standard Methods for the Examination of Water and Wastewater. 21th Edition. Wasghington D.C., 2005.

AYRES, M.; AYRES Jr., M.; AYRES, D. L.; SANTOS, A. A. S. Bioestat Versão 5.0. Belém: Sociedade Civil Mamirauá, MCT - CNPq, 2008.

CARMO, L. R.; DAGNINO, R. S.; JOHANSEN, I. C. Transição demográfica e do consumo urbano de água no Brasil. Revista Brasileira de Estudos de População, v. 31, n. 1, p. 169-190, 2014.

CECH, T. V. Recursos hídricos: história, desenvolvimento, política e gestão. Rio de Janeiro: LTC, 2013.

COMPANHIA AMBIENTAL DO ESTADO DE SÃO PAULO - CETESB. Variáveis de qualidade de água. São Paulo, 2009. Disponível em: <http://www.cetesb.sp.gov.br/ Agua/rios/variaveis.asp\#transparencia>. Acesso em: 10 mar. 2015.

COMPANHIA AMBIENTAL DO ESTADO DE SÃO PAULO - CETESB. Índices de Qualidade das Águas. São Paulo, 2013. Disponível em: <http://www.cetesb.sp.gov.br/ userfiles/file/agua/aguas-superficiais/aguas-interiores/documentos/indices/01.pdf $>$.

Acesso em: 18 nov. 2013.

CONSELHO NACIONAL DE MEIO AMBIENTE - CONAMA. Resolução nº 357, de 17 de março de 2005: dispõe sobre a classificação dos corpos de água e diretrizes ambientais para o seu enquadramento, bem como estabelece as condições e padrões de lançamento de efluentes, e dá outras providências. Diário Oficial [da] União, Brasília,

CUNHA, A. C.; CUNHA, H. F.; SOUZA, J. A.; NAZARÉ, A.; PANTOJA, S. Monitoramento de Águas Superficiais em Rios Estuarinos do Estado do Amapá sob Poluição Microbiológica. Boletim do Museu Paraense Emílio Goeldi. Ciências Naturais, v. 1, n. 1, p. 191-199, 2005.

ESTEVES, F. A.; MENEZES, C. F. S. Papel da Água e da Limnologia na sociedade Moderna. In: ESTEVES, F. A. Fundamentos de limnologia. 3. ed. Rio de Janeiro: Interciência, 2011. p. 62-73.

FAGUNDES, B. V.; CUNHA, A. C.; RODRIGUES, A. S. L.; SIQUEIRA, E. Q. Monitoramento sazonal da qualidade da água do rio Araguari/AP. Revista Biociências, v. 16, n. 1, p. 57-72, 2010.

GUERRA, A. J. T. Geomorfologia urbana. Rio de Janeiro: Bertarand Brasil, 2011.

HADDAD, E. A.; MAGALHÃES JÚNIOR, A. P. Influência antrópica na qualidade da água da bacia hidrográfica do rio São Miguel, carste do alto São Francisco, Minas Gerais. Geosul, v. 25, n. 49, p. 79-102, 2010.

HOMMA, A. K. Amazônia: como aproveitar os benefícios da destruição? Estudos Avançados, v. 19, n. 54, p. 115-135, 2005. http://dx.doi.org/10.1590/S010340142005000200007 
INSTITUTO BRASILEIRO DE GEOGRAFIA E ESTATÍSTICA - IBGE. Censo Demográfico 2010. Disponível em: <http://www.cidades.ibge.gov.br/xtras/ perfil.php?lang=\&codmun=16 0030\&search $=\mid$ infinf\%E1ficos:-informa\%E7\%F5escompletas>. Acesso em: 2 fev. 2014.

INSTITUTO NACIONAL DE METEREOLOGIA - INMET (Brasil). Normas climatológicas do Brasil. Brasília, 2014. 465p.

MACHADO, N. G.; NASSARDEN, D. C. S.; SANTOS, F.; BOAVENTURA, I. C. G.; PERRIER, G.; SOUZA, F. S. C. et al. Chironomus larvae (Chironomidae: Diptera) as water quality indicators along an environmental gradient in a neotropical urban stream. Revista Ambiente \& Água, v. 10 n. 2, p. $298 \quad$ - 309, 2015. http://dx.doi.org/10.4136/ambi-agua.1533

MARINS, R. V.; PAULA FILHO, F. J.; ROCHA, C. A. S. Geoquímica de fósforo como indicadora da qualidade ambiental e dos processos estuarinos do rio Jaguaribe - Costa nordeste oriental brasileira. Química Nova, v. 30, n. 5, 1208-1214, 2007. http://dx.doi.org/10.1590/S0100-40422007000500029

MONTEIRO, M. C.; PEREIRA, L. C. C.; GUIMARÃES, D. O.; COSTA, R. M.; SOUZAFILHO, P. W. M.; VIEIRA, S. R. et al. Influence of natural and anthropogenic conditions on the water quality of the Caeté river estuary (North Brazil). Journal of Coastal Research, v. 64, p. 1535 - 1539, 2011.

OLIVEIRA, B. S. S.; CUNHA, A. C. Correlação entre qualidade da água e variabilidade da precipitação no sul do Estado do Amapá. Revista Ambiente \& Água, v. 9, n. 2, p. 261275, 2014. http://dx.doi.org/10.4136/ambi-agua.1287

PEREIRA, L. C. C.; MONTEIRO, M. C.; GUIMARÃES, D. O.; MATOS, J. B., COSTA, R. M. Seasonal effects of wastewater to the water quality of the Caeté river estuary, Brazilian Amazon. Anais da Academia Brasileira de Ciências, v. 82, n. 2, p. 467-478, 2010a.

PEREIRA, S. F. P.; COSTA, A. C.; CARDOSO, E. S. C.; CORRÊA, M. S. S.; ALVES, D. T. V.; MIRANDA, R. G. et al. Condições de potabilidade da água consumida pela população de Abaetetuba-Pará. Revista de estudos ambientais, v. 12, n. 1, p. 50-62, $2010 b$.

PINHEIRO, L. A. R.; CUNHA, A. C.; CUNHA, H. F. A.; SOUZA, L. R.; BILHALVA, J. S.; BRITO, D. C. et al. Aplicação de Simulação computacional à dispersão de poluentes no baixo rio Amazonas: potenciais riscos à captação de água na orla de Macapá. Amazônia: Ciência \& Desenvolvimento, v. 4, n. 7, p. 27-44, 2008.

PONTES, P. P.; MARQUES, A. R.; MARQUES, G. F. Efeito do uso e ocupação do solo na qualidade da água na micro-bacia do Córrego Banguelo - Contagem. Revista Ámbiente \& Água, v. 7, n. 3, p. 183-194, 2012. http://dx.doi.org/10.4136/ambiagua.962

PORTUGAL JÚNIOR, P. S.; REYDON, B. P.; PORTUGAL, N. S. As águas minerais no Brasil: uma análise do mercado e da institucionalidade para uma gestão integrada e sustentável. Revista Ambiente \& Água, v. 10, n. 2, p. 413 - 430, 2015. http://dx.doi.org/10.4136/ambi-agua.1357 
RODRIGUES, L. A.; TORRES, N. H.; TORNISIELO, V. L.; FERREIRA, L. F. R.; MARANHO, L.A. Determination of toxicity assays, trophic state index, and physicochemical parameters on Piracicaba River and Itapeva Stream. Revista Ambiente \& Água, v. 10 n. 2, p. 310 - 317, 2015. http://dx.doi.org/10.4136/ambiagua. 1387

SABINO, C. V. S.; ABREU, J. F.; LOBATO, W.; SABINO, G. S.; KNUP, E. A. N. Análise de alguns aspectos da qualidade da água da Bacia do Rio Paraopeba utilizando estatística Multivariada. Revista de Biologia e Ciencias da Terra, v. 8, n. 2, p. 6-18, 2008.

SANTI, G. M.; FURTADO, C. M.; MENEZES, R. S. A.; KEPPELER, E. C. Variabilidade espacial de parâmetros e indicadores de qualidade da água na sub-bacia hidrográfica do igarapé São Francisco, Rio Branco, Acre, Brasil. Ecologia Aplicada, v. 11, n.1, p. 2331, 2012.

SANTOS, E. R. C. Urbanização e Rede Urbana na Amazônia Setentrional Amapaense/Ap. Revista Formação Online, v. 2, n. 19, p. 107 -131, 2012.

SANTOS, M. L. S.; MUNIZ, K.; FEITOSA, F. A. N.; BARROS NETO, B. Estudo das diferentes formas de fósforo nas águas da plataforma continental do Amazonas. Química Nova, São Paulo, v. 30, n. 3, p. 569-573, maio/jun. 2007. http://dx.doi.org/10.1590/S0100-40422007000300012

SANTOS, M. L. S.; SARAIVA, A. L. L.; DELFINO, I. B.; ANTUNES, L. C.; BATISTA, R. M. M.; ALVES, I. C. C. Avaliação das Formas de Fósforo nos Sedimentos Superficiais da Plataforma Continental do Rio Amazonas. Revista da Gestão Costeira Integrada, v 10, n. 4, p.589-596, 2010.

SILVA, A. E. P.; ANGELIS, C. F.; MACHADO, L. A. T.; WAICHAMAN, A. V. Influência da precipitação na qualidade da água do Rio Purus. Acta Amazonica, v. 38, n. 4, p. 733-742, 2008. http://dx.doi.org/10.1590/S0044-59672008000400017

SILVA, D. F.; MOREJON, C. F. M.; LESS, F. R. Prospecção do panorama do saneamento rural e urbano no Brasil. Revista Eletrônica do Mestrado em Educação Ambiental, v. especial, p. 245-257, 2014a.

SILVA, E. S.; ALBUQUERQUE, M. F. C. Drenagem Urbana de Macapá: um estudo em geografia da Saúde. In: ENCONTRO DE GEÓGRAFOS DA AMÉRICA LATINA, 14., 8-12 abr. 2013, Peru. Anais... Peru: UGI, 2013.

SILVA, L. M.; MORALES, G. P.; LIMA, A. M. M. de. Avaliação da qualidade das águas superficiais dos mananciais do Utinga e dos rios Guamá e Aurá, Belém, Pará. Revista Enciclopédia Biosfera, v. 10, n. 18, p. 3161-3179, 2014b.

SILVA, R. C. A.; ARAÚJO, T. M. Qualidade da água do manancial subterrâneo em áreas urbanas de Feira de Santana (BA). Ciência \& Saúde Coletiva, Rio de Janeiro, v. 8, n. 4, p.1019-1028, 2003. http://dx.doi.org/10.1590/S1413-81232003000400023

SIQUEIRA, G. W.; APRILE, F.; MIGUÉIS A. M. Diagnóstico da qualidade da água do rio Parauapebas (Pará - Brasil). Acta Amazonica, v. 42, n. 3, p. 413-422, 2012. http://dx.doi.org/10.1590/S0044-59672012000300014 
SOUSA, T. B.; CUNHA, E. B. Valoração econômica ambiental: uma estimativa do valor de uso e valor de não uso do rio Amazonas no litoral da capital amapaense. Revista Meio Ambiente e Sustentabilidade, v. 4, n. 2, p. 264-286, 2013.

TAKIYAMA, L. R.; RODRIGUES P. A.; CALDAS, U. M. Impacto ambiental em igarapés urbanos nas cidades de Macapá-AP e Santana-AP: variações da qualidade da água em função das marés. In: REUNIÃO ANUAL DA SBPC/AMAPÁ, 2007. Macapá. Anais... [S.1.]: IEPA, 2007.

TAKIYAMA, L. R.; SILVA, A. Q.; COSTA, W. J. P; NASCIMENTO, H.S. Qualidade das águas das Ressacas das Bacias do Igarapé da Fortaleza e do rio Curiaú. In: TAKIYAMA, L. R.; SILVA, A. Q. da (Orgs). Diagnóstico das ressacas de Estado do Amapá: Bacias do Igarapé da Fortaleza e do Curiaú. Macapá: CPAQ/IEPA; DGEO/SEMA, 2003. p. 81-104.

TARGA, M. S.; BATISTA, G. T. Benefits and legacy of the water crisis in Brazil. Revista Ambiente \& Água, v. 10 n. 2, p. 234 -239, 2015. http://dx.doi.org/10.4136/ambiagua. 1629

TAVARES, J. P. N. Características da climatologia de Macapá-AP. Caminhos de Geografia, Uberlândia v. 15, n. 50, p. 138-151, 2014.

TORRES, A. M.; EL-ROBRINI, M. Amapá. In: MUEHE, D. (Org.). Erosão e Progradação do litoral Brasileiro. Brasília: MMA, 2006. p. 11-40.

TUCCI, C. E. M. Águas urbanas. Estudos Avançados, v. 22, n. 63, p. 97-112, 2008.

TUNDISI, J. G.; TUNDISI, T. M. Limnologia. São Paulo: Oficina de Textos, 2008.

VON SPERLING, M. Estudos e modelagem da qualidade da água de rios. Belo Horizonte: Departamento de Engenharia Sanitária e Ambiental; Universidade Federal de Minas Gerais, 2008. 